\title{
A novel GDAP1 Q218E mutation in autosomal dominant Charcot-Marie-Tooth disease
}

\author{
Ki Wha Chung $\cdot$ Seung Min Kim $\cdot$ Il Nam Sunwoo $\cdot$ Sun Young Cho $\cdot$ \\ Su Jin Hwang · Joonki Kim · Sung Hee Kang • Kee-Duk Park • \\ Kyoung-Gyu Choi $\cdot$ Il Saing Choi $\cdot$ Byung-Ok Choi
}

Received: 28 October 2007/ Accepted: 3 January 2008/Published online: 31 January 2008

(C) The Japan Society of Human Genetics and Springer 2008

\begin{abstract}
A wide range of phenotypes have been reported in autosomal recessive (AR) Charcot-Marie-Tooth disease (CMT) patients carrying mutations in the gangliosideinduced differentiation-associated protein 1 (GDAPl) gene, such as axonal, demyelinating, and intermediate forms of AR CMT. There have been very few reports of GDAP1 mutations in autosomal dominant (AD) CMT. Here, we report an AD CMT family with a novel Q218E mutation in the GDAPl gene. The mutation was located within the well-conserved glutathione S-transferase (GST) core region and co-segregated with the affected members in the pedigree. The affected AD CMT individuals had a later disease onset and much milder phenotypes than the AR CMT patients, and the histopathologic examination revealed both axonal degeneration and demyelination.
\end{abstract}

Keywords Autosomal dominant - Charcot-Marie-Tooth disease · Ganglioside-induced differentiation-associated protein $1 \cdot$ Mutation Phenotype

K. W. Chung $\cdot$ J. Kim $\cdot$ S. H. Kang

Department of Biological Science,

Kongju National University, Gongju, South Korea

S. Y. Cho · S. J. Hwang · K.-D. Park - K.-G. Choi ·

B.-O. Choi $(\square)$

Department of Neurology and Ewha Medical Research Center,

Ewha Womans University, School of Medicine,

70 Jongno 6-ga, Jongno-gu, Seoul 110-783, South Korea

e-mail: bochoi@ewha.ac.kr

S. M. Kim · I. N. Sunwoo

Department of Neurology, Yonsei University,

College of Medicine, Seoul, South Korea

I. S. Choi

Department of Neurology, National Health Insurance

Corporation Ilsan Hospital, Goyang, South Korea

\begin{abstract}
Abbreviations
AD Autosomal dominant

AR Autosomal recessive

CMT Charcot-Marie-Tooth disease

GDAP1 Ganglioside-induced differentiation-associated protein 1

NCV Nerve conduction velocity
\end{abstract}

\section{Introduction}

Charcot-Marie-Tooth disease (CMT) is the most common form of inherited peripheral neuropathy. Mutations in the ganglioside-induced differentiation-associated protein 1 (GDAPl) gene are associated with a wide range of phenotypes, such as axonal autosomal recessive (AR) CMT (OMIM 607731, 607831) (Cuesta et al. 2002; Birouk et al. 2003), demyelinating AR CMT (OMIM 214400) (Baxter et al. 2002), and intermediate AR CMT (OMIM 608340) (Nelis et al. 2002; Senderek et al. 2003). Autosomal recessive CMT with GDAP1 mutations is associated with a severe phenotype that is characterized by a rapidly progressive weakness that usually begins before the age of 3 years and eventually leads to an inability to walk by the second or third decade of life (Bernard et al. 2006). The recent observation of AD CMT by Claramunt et al. (2005) showed much milder phenotypes and onset during the second decade of life; however, no pathologic type of $\mathrm{AD}$ CMT has been reported.

GDAPl is expressed in neurons and Schwann cells, which implies that GDAPI may play a fundamental role during the development and myelination of the peripheral nervous system (Cuesta et al. 2002; Nelis et al. 2002). Moreover, recent functional studies have shown 
that the GDAP1 protein is also localized in the mitochondria (Niemann et al. 2005; Pedrola et al. 2005). Although the pathophysiological mechanisms underlying their activities remain to be elucidated, GDAP1 might play a variety of roles in the development of the peripheral nervous system.

In this study, we identified a novel GDAP1 Q218E mutation that seems to be associated with two AD CMT patients in a family of Korean descent. They had very mild phenotypes, with the age of disease onset in the second and third decades and the histopathologic features of axonal degeneration and demyelination.

\section{Patients and methods}

\section{Subjects}

This study involved samples from 217 unrelated CMT patients of Korean descent. In particular, all familial members of the FC8 pedigree were included in this study (Fig. 1a). An additional 187 healthy controls were recruited from the Neurological Department. All participants provided written informed consent to take part in the study, which was approved by the Ethics Committee of Ewha Womans University Hospital.

\section{Clinical assessment}

\section{Patient 1}

The proband (M/68 years; Fig. 1a, I-1) was admitted to the Department of Neurology at the age of 58 years. He was noted to have gait problems at 25 years of age. His gait was clumsy, and his ankles appeared to be weak. He apparently began to notice atrophy of his hand muscle in his fifties. He showed no signs of hoarseness, diaphragmatic paralysis, or pyramidal tract involvement, and his intelligence was normal. Neurological examination at the age of 68 years showed distal wasting and muscle weakness in the lower limbs and both hands; however, he maintained the ability to walk on his own. His abilities to sense vibrations and feel pain were reduced in the distal upper and lower limbs. Muscle stretch reflexes were present, with the exception of the knee and ankle reflexes. It is noteworthy that the median and ulnar motor nerve conduction velocities (NCVs) and compound motor action potentials (CMAPs) were normal or mildly reduced and that NCVs performed at 11-year intervals showed very slow progression, which was consistent with his clinical features (Table 1).

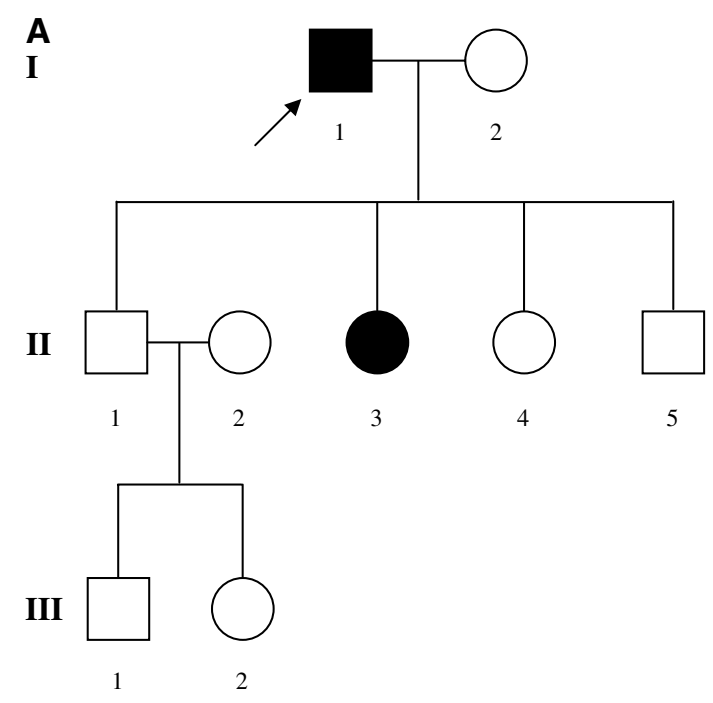

B

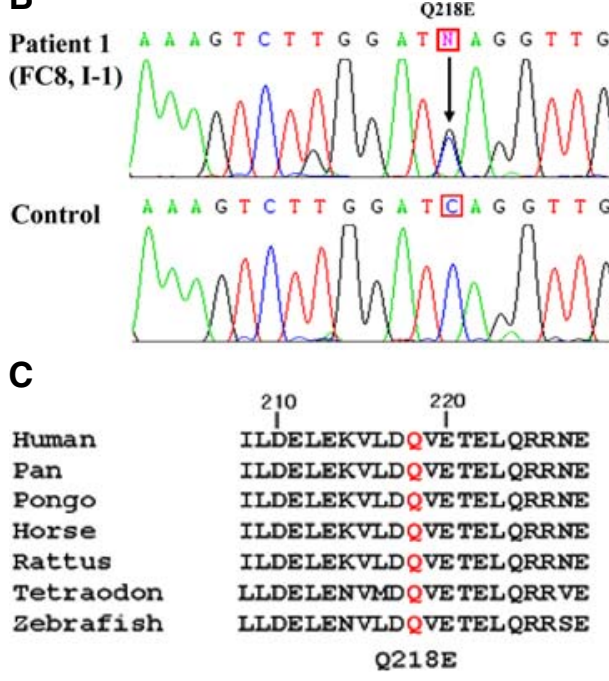

Fig. 1 a Pedigree of the FC8 family with a ganglioside-induced differentiation-associated protein 1 (GDAP1) mutation. The open symbols represent the unaffected females (open circle) and males (open square), and the filled symbols represent the affected male (filled square) and female (filled circle). Arrow indicates the proband. b Chromatograms of a Q218E (c.C652G) mutation. c Conservation of the amino acid at the Q218E mutation site in different species. Multiple alignment of the GDAP1 family was performed with the ClustalX ver. 1.83 program

\section{Patient 2}

The daughter of Patient 1 (F/36 years; Fig. 1a, II-3) was admitted at 17 years of age due to difficulty in walking. She showed no delay in developmental milestones. She began to experience progressive gait abnormalities at 16 years of age. She was able to recall that she began to experience symptoms of hand muscle atrophy at the age of 23 years. She had no hoarseness or diaphragmatic paralysis. Neurological examination at the age of 36 years revealed moderate weakness and atrophy of the distal 
Table 1 Electrophysiological findings in autosomal dominant Charcot-Marie-Tooth patients with a ganglioside-induced differentiation-associated protein 1 mutation

\begin{tabular}{|c|c|c|c|c|c|c|c|c|c|}
\hline \multirow[t]{2}{*}{ Patient } & \multirow{2}{*}{$\begin{array}{l}\text { Age at } \\
\text { exam (years) }\end{array}$} & \multirow[t]{2}{*}{ Site } & \multicolumn{4}{|c|}{ Motor nerve conduction velocity $(\mathrm{m} / \mathrm{s})$} & \multicolumn{3}{|c|}{ Sensory nerve conduction velocity $(\mathrm{m} / \mathrm{s})$} \\
\hline & & & Median & Ulnar & Peroneal & Tibial & Median & Ulnar & Sural \\
\hline Patient 1 (Fig. 1a, I-1) & 68 & Right & $51.0(8.8)$ & $50.2(9.4)$ & NR & NR & $37.8(6.0)$ & $36.4(2.1)$ & NR \\
\hline Patient 2 (Fig. 1a, II-3) & 36 & Right & $46.7(4.5)$ & $46.9(5.3)$ & NR & NR & $29.9(9.1)$ & $25.0(5.9)$ & NR \\
\hline
\end{tabular}

The amplitudes of evoked responses are given in parenthesis [for motor nerve conduction velocities (NCVs) by mV and for sensory NCVs by $\mu \mathrm{V}$ ]. Normal NCV values: motor median nerve, $\geq 50.5 \mathrm{~m} / \mathrm{s} ;$ ulnar nerve, $\geq 51.1 \mathrm{~m} / \mathrm{s} ;$ sensory median nerve, $\geq 39.3 \mathrm{~m} / \mathrm{s} ;$ ulnar nerve $\geq 37.5 \mathrm{~m} / \mathrm{s}$. Normal amplitude values: motor median nerve, $\geq 6 \mathrm{mV}$; ulnar nerve, $\geq 8 \mathrm{mV}$; sensory median nerve, $\geq 8.8 \mu \mathrm{V}$; ulnar nerve, $\geq 7.9 \mu \mathrm{V} ; N R$, not recordable

muscles of the upper and lower limbs; however, she was also able to walk without any assistance. Pes equinovarus was noted, but scoliosis was not found. All of her sensory modalities, including vibratory sense and pain appreciation, were impaired distally in the upper and lower limbs. Stretch reflexes were present, except for the ankle reflexes. Nerve conduction studies and needle EMG indicated the presence of an axonal polyneuropathy (Table 1).

\section{Mutation screening}

Genomic DNA was extracted from whole blood samples using a QIAamp DNA blood kit (Qiagen, Hilden, Germany). The mutation in the GDAPl gene was confirmed by DNA sequencing of all exons and contiguous flanking intronic sequences. The sequences were determined by sequencing the purified PCR products using an ABI 3100 automatic sequencing analyzer (Applied Biosystems, Foster City, CA). We used the SEQSCAPE (ver. 2.1) program (Applied Biosystems) to detect the sequence variation and confirmed the sequence variations by analyzing both strands of DNA.

\section{Results and discussion}

The screening of the GDAPl gene in this Korean CMT family (FC8) led to the discovery of a heterozygous form of an unreported novel single missense mutation, Q218E (c.C625G). This mutation was found in two affected familial members, the proband (Fig. 1a, I-1) and her daughter (Fig. 1a, II-3), but it was not found in the unaffected members. This mutation was not found in any of 374 control chromosomes. No other causative mutation was found in other exons and in their flanking intron regions in both affected members. Consequently, we were able to rule out the possibility of compound heterozygosity of GDAP1 mutations. In this family, the heterozygous $\mathrm{C}-\mathrm{G}$ transversion (c.C625G) mutation co-segregated with the disease in the FC8 family in an autosomal dominant (AD) manner
(Fig. 1a). This nucleotide transition resulted in a substitution of glutamic acid for glutamine (Fig. 1b). This Q218E mutation is located within the glutathione S-transferase (GST) core region, which is highly conserved in most GST proteins (Fig. 1c). No other causative mutation was found in PMP22, MPZ, LITAF, NEFL, CX32, MFN2, HSP22, HSP27, BSCL2, and DNM2 in both affected members of the FC8 family.

The proband underwent a sural nerve biopsy at the age of 68 years, 43 years after the onset of the disease. An axonal process, characterized by the loss of myelinated fibers, especially large-diameter ones $(>8 \mu \mathrm{m})$, and occasional onion bulb formations were observed. The unmyelinated fibers appeared to be better preserved than the myelinated fibers, and the thickness of the myelin sheath was reduced in comparison to the axonal diameter (Fig. 2a). In addition, a regenerative cluster consisting of adjacent thinly myelinated axons surrounded by a concentric proliferation of Schwann cell cytoplasmic fragments was visible (Fig. 2b). Electron microscopic examinations confirmed the presence of the significant concentrically enlarged Schwann cytoplasmic and basal lamina fragments enclosing an unmyelinated axon (Fig. 2 c) or thinly myelinated axon (Fig. 2d).

Patients with AD GDAPl mutations are very rare (Claramunt et al. 2005); however, we believe that the $\mathrm{Q} 218 \mathrm{E}$ mutation in the $\mathrm{FC} 8$ family is relevant to $\mathrm{AD}$ CMT due to the following observations: (1) co-segregation of the mutation with affected members in the pedigree, (2) no detection of the same mutation in 374 control chromosomes, (3) good conservation of the amino acids at the mutation site among different species, (4) no causative mutation in most known CMT genes in the family, and (5) phenotypic similarity with the Spanish AD CMT patients reported by Claramunt et al. (2005). Some individuals having frameshift or nonsense mutations in the heterozygous state have been reported as normal (Stojkovic et al. 2004; Baránková et al. 2007); however, the Q218E mutation in this study seems to be less drastic, but symptomatic. One plausible explanation is that heavily damaged GDAP1 proteins would be completely 

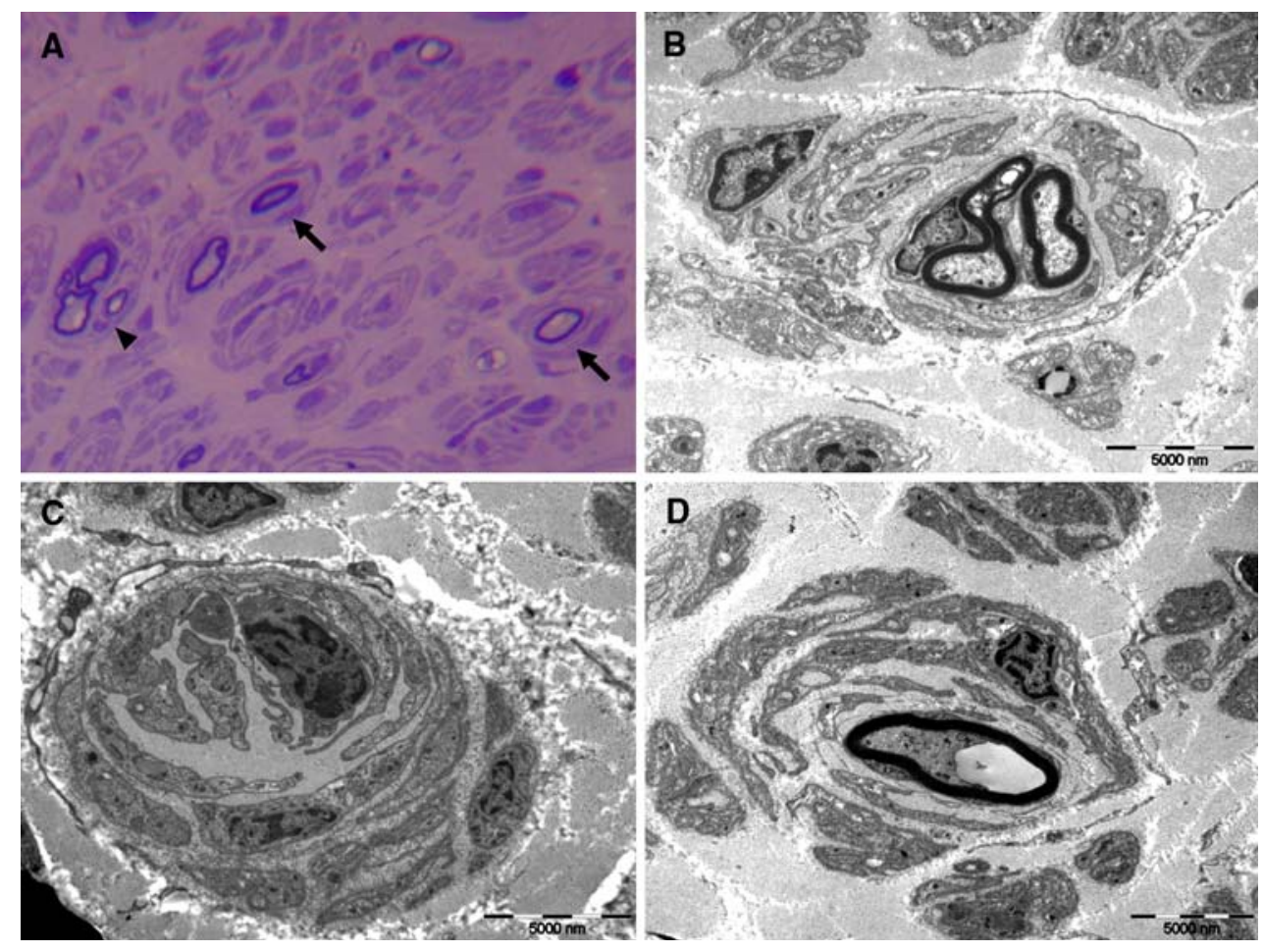

Fig. 2 Light microscopic (a) and ultrastructure (b-d) findings. a Transverse semi-thin section of the sural nerve biopsy of patient 1 at 68 years of age, after a disease duration of 43 years. The number of large myelinated fibers is severely reduced, and the thickness of the myelin sheath is reduced in comparison to the axonal diameter. Occasional small onion bulb formations (arrows) and a regenerative cluster (arrowhead) are observed (toludine blue; original

nonfunctional but that the Q218E GDAP1 mutant protein in this study would reveal a dominant negative effect or partial loss of function, so it may inhibit the function of normal GDAP1 protein.

Because the GDAPl gene is expressed in Schwann cells and neurons, it is associated with a wide spectrum of neuropathologic abnormalities, leading to the possible existence of several types of CMT, such as axonal, demyelinating, or intermediate AR CMT (Baxter et al. 2002; Cuesta et al. 2002; Senderek et al. 2003). In this study, sural nerve biopsy of our AD CMT patient (Fig. 1a, I-1) demonstrated both an axonal and demyelinating form of neuropathy. The axonal degeneration and demyelination produced by the GDAP1 mutation can be explained by the fact that GDAP1 is involved in the developmental steps needed for the formation and maintenance of myelin. Thus, GDAP1 mutations will add to our understanding of the biopsy findings in the AD CMT patient.

Most AR CMT patients with the GDAPl gene mutation show a very early disease onset, usually during infancy, with a severe phenotype that can include vocal cord paresis, diaphragmatic paralysis, or kyphoscoliosis (Birouk et al. 2003; Stojkovic et al. 2004). The majority of patients magnification $\times 400$ ). b A regenerative cluster consisting of two adjacent thinly myelinated axons surrounded by flattened Schwann cell processes. c Significant concentric proliferation of Schwann cell cytoplasmic and basal lamina fragments around an unmyelinated axon is visible. d An onion bulb formation can be seen with concentric cytoplasmic Schwann cell processes around thinly myelinated fibers

with this type of AR CMT have delayed developmental milestones due to the marked weakness and wasting of the distal muscles of the four limbs, which lead to severe disability and the use of a wheelchair at the beginning of their second decade (Bernard et al. 2006). In addition, the duality of phenotypes was displayed within an AR CMT family having the same mutation site in GDAPl (Nelis et al. 2002). However, it has been reported that AD CMT patients with the R120W GDAP1 mutation experience disease onset at the end of their second decade, show very slow disease progression, and have a much milder phenotype than patients with AR CMT (Claramunt et al. 2005). In our study, the phenotypes of our AD CMT patients were very similar to those of the Spanish AD CMT patients with the R120W GDAP1 mutation. Patient 1 was in his midthird decade at disease onset, and his daughter began to show signs of the disease during her second decade. The proband (M/68) and her daughter (F/36) are currently able to walk on their own and need no orthopedic devices. Even though further evaluations are needed to confirm the hypothesis, the clinical features of GDAP1 mutations may differ between patients with AR CMT and those with $\mathrm{AD}$ CMT. 
Acknowledgments This work was supported by the Brain Korea 21 project, Ministry of Education, the Korea Research Foundation Grant funded by the Korean Government (MOEHRD) (KRF-2007-313E00397), and the Korea Research Foundation (Grant No. KRF-2005041-F00025).

\section{References}

Baránková L, Vyhnálková E, Züchner S, Mazanec R, Sakmaryová I, Vondrácek P, Merlini L, Bojar M, Nelis E, De Jonghe P, Seeman $\mathrm{P}$ (2007) GDAP1 mutations in Czech families with early-onset CMT. Neuromuscul Disord 17:482-489

Baxter RV, Ben Othmane K, Rochelle JM, Stajich JE, Hulette C, Dew-Knight S, Hentati F, Ben Hamida M, Bel S, Stenger JE, Gilbert JR, Pericak-Vance MA, Vance JM (2002) Gangliosideinduced differentiation-associated protein-1 is mutant in Charcot-Marie-Tooth disease type 4A/8q21. Nat Genet 30:21-22

Bernard R, De Sandre-Giovannoli A, Delague V, Levy N (2006) Molecular genetics of autosomal-recessive axonal CharcotMarie-Tooth neuropathies. Neuromolecular Med 8:87-106

Birouk N, Azzedine H, Dubourg O, Muriel MP, Benomar A, Hamadouche T, Maisonobe T, Ouazzani R, Brice A, Yahyaoui M, Chkili T, Le Guern E (2003) Phenotypical features of a Moroccan family with autosomal recessive Charcot-Marie-Tooth disease associated with the S194X mutation in the GDAP1 gene. Arch Neurol 60:598-604

Claramunt R, Pedrola L, Sevilla T, Lopez de Munain A, Berciano J, Cuesta A, Sanchez-Navarro B, Millan JM, Saifi GM, Lupski JR, Vilchez JJ, Espinos C, Palau F (2005) Genetics of CharcotMarie-Tooth disease type 4A: mutations, inheritance, phenotypic variability, and founder effect. J Med Genet 42:358-365
Cuesta A, Pedrola L, Sevilla T, Garcia-Planells J, Chumillas MJ, Mayordomo F, LeGuern E, Marin I, Vilchez JJ, Palau F (2002) The gene encoding ganglioside-induced differentiation-associated protein 1 is mutated in axonal Charcot-Marie-Tooth type 4A disease. Nat Genet 30:22-25

Nelis E, Erdem S, Van Den Bergh PY, Belpaire-Dethiou MC, Ceuterick C, Van Gerwen V, Cuesta A, Pedrola L, Palau F, Gabreels-Festen AA, Verellen C, Tan E, Demirci M, Van Broeckhoven C, De Jonghe P, Topaloglu H, Timmerman V (2002) Mutations in GDAP1: autosomal recessive CMT with demyelination and axonopathy. Neurology 59:1865-1872

Niemann A, Ruegg M, La Padula V, Schenone A, Suter U (2005) Ganglioside-induced differentiation associated protein 1 is a regulator of the mitochondrial network: new implications for Charcot-Marie-Tooth disease. J Cell Biol 170:1067-1078

Pedrola L, Espert A, Wu X, Claramunt R, Shy ME, Palau F (2005) GDAP1, the protein causing Charcot-Marie-Tooth disease type $4 \mathrm{~A}$, is expressed in neurons and is associated with mitochondria. Hum Mol Genet 14:1087-1094

Senderek J, Bergmann C, Ramaekers VT, Nelis E, Bernert G, Makowski A, Zuchner S, De Jonghe P, Rudnik-Schoneborn S, Zerres K, Schroder JM (2003) Mutations in the gangliosideinduced differentiation-associated protein-1 (GDAPl) gene in intermediate type autosomal recessive Charcot-Marie-Tooth neuropathy. Brain 126:642-649

Stojkovic T, Latour P, Viet G, de Seze J, Hurtevent JF, Vandenberghe A, Vermersch P (2004) Vocal cord and diaphragm paralysis, as clinical features of a French family with autosomal recessive Charcot-Marie-Tooth disease, associated with a new mutation in the GDAP1 gene. Neuromuscul Disord 14:261-264 